\title{
In Defense of Narrative Authenticity
}

\section{Response to the discussion of Pugh, Maslen \& Savulescu and Nyholm \& O’Neill}

Muriel Leuenberger, muriel.leuenberger@unibas.ch,University of Basel

Accepted Manuscript, full article appears in Cambridge Quarterly of Healthcare Ethics, published by

Cambridge University Press, (C) Cambridge University Press

Leuenberger, M. In Defense of Narrative Authenticity. Cambridge Quarterly of Healthcare Ethics Forthcoming.

https://www.cambridge.org/core/journals/cambridge-quarterly-of-healthcare-ethics

\begin{abstract}
This paper ties in with the ongoing debate on authenticity and the influence of Deep Brain Stimulation (DBS) on authenticity, in particular with the exchange between Pugh et al. and Nyholm and O'Neill. Both argue against a narrative approach to authenticity, which will be defended in this paper. First, it is shown that the critique they offer does not hold against a more refined view on narrativism. Second, a narrative approach to authenticity is introduced. To be authentic is to have a self-narrative 1) that is sustainable in the sense that it is easy to uphold because it is not in tension with one's lived experience, and 2) that constitutes a well-defined person, which means that vastly different, more coherent and intelligible counternarratives are excluded. Third, the advantages of a narrative account of authenticity are discussed, including a short overview of the influence of DBS on narrative authenticity.
\end{abstract}

\section{Introduction}

The development and increased use of ever more potent and specific methods for neural modification, in particular Deep Brain Stimulation (DBS) and psychotropic drugs, contributed to a renewed interest in the idea of authenticity. DBS is a neurosurgical procedure which uses implanted electrodes to stimulate targeted brain areas for the treatment of mainly Parkinson's Disease and movement disorders and at an experimental stage for psychiatric disorders such as Obsessive-Compulsive Disorder (OCD), Anorexia Nervosa (AN) and depression. DBS is of particular interest in the context of authenticity because

I would like to thank Marya Schechtman and Markus Wild for stimulating discussions and helpful comments on this material. This work was supported by Doc.CH grant P0BSP1_172100 of the Swiss National Science Foundation. 
of its potential to induce abrupt changes in personality, identity, autonomy and felt authenticity. ${ }^{1}$ Some patients have reported a feeling of self-alienation following DBS treatment while others felt more authentic. Mental disorders add another issue regarding authenticity because many patients suffer from substantial inner conflict, leading them to shift between different mindsets, for instance a depressed and a non-depressed one. They turn to the concept of authenticity in the hope of finding guidance to resolve this kind of conflict. ${ }^{2}$ The following is a response to the ongoing discussion between Jonathan Pugh et al. ${ }^{3}$ and Sven Nyholm and Elisabeth O'Neill ${ }^{4}$ about the effects of DBS on authenticity, in particular in the context of AN. After an introduction into the debate so far, narrativism is defended against the offered critique. The main part of the paper introduces a narrative approach to authenticity. It is followed by a discussion on the advantages of narrative authenticity, including a short overview of the influence of DBS on narrative authenticity.

\section{The debate so far}

Both, Pugh et al. and Nyholm and O'Neill aim at establishing an account of authenticity which can provide guidance to people struggling with shifting mindsets and which fits patients' experience and use of the concept of authenticity. They define authenticity as living in accordance with one's "true self". The true self consists of one's core characteristics (i. e. core traits, values, preferences, goals, dispositions). Some approaches to authenticity see the true self as a fixed, individual essence, meaning that authenticity is all about self-discovery. ${ }^{5}$ In contrast to this essentialistic view, there are existentialistic approaches which understand authenticity as a matter of choice and self-creation. ${ }^{6}$ Individuals should freely create themselves, unfettered by the demands of alleged essences or social norms. A dual-basis view, endorsed by both sides of the discussion as well as by the narrative authenticity view introduced here, combines elements of self-discovery and of self-creation.

Pugh et al. argue that the true self is "constituted by the cohering elements of the individual's

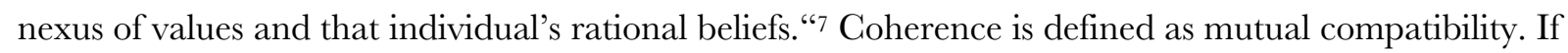
a person has incompatible desires, he needs to decide which desire is more valuable. This preference becomes a part of the true self. Some individual characteristics are more or less fixed. But it is up to you to decide which of those fixed characteristics you disvalue and try to change and which ones you endorse and foster. Pugh et al. see their approach as diachronic because values are most plausibly understood in a diachronic sense. Nyholm and O'Neill agree that some aspects of ourselves are given whereas others are under our control. In the case of shifting mindsets, we should consider the one which includes more "tolerable values" as representing the true self. Tolerable values are those which are viewed as sensible or legitimate, even by someone who does not hold them. ${ }^{8}$ They argue that regarding the mindset with more shared values as representing the true self makes sense because it helps to sustain relationships. Authenticity is seen as a synchronic notion, meaning that it is possible to judge whether someone is authentic without reference to that person's past, because "we can ask, for example, whether our true self is currently shining through."9 
Both sides of the debate criticize narrative views. Narrativism is based on the idea that humans integrate their experiences into a linear, internalized and evolving story. By being part of an ongoing story, single experiences become meaningful. An individual's life is not just composed of disjointed, rhapsodic episodes; they are integrated into a broader context. A self-narrative is a story telling one's life-events from a personal perspective, reflecting character traits, goals and values. Self-narratives differ from a chronology insofar as they connect events in a meaningful way, highlight more important events, include selective editing, add personal perspective and contextualize episodes. A self-narrative provides reasons which include motives and intentions, thereby going beyond just efficient causes. It differs from typical literary narratives insofar as not everything that happens in one's life has a meaning. Life is full of coincidences that do not call for further explanation. In a similar vein, a self-narrative does not need to have a grand scheme or an overarching unifying topic. Furthermore, having a self-narrative does not imply that I consciously tell my whole life-story to myself or others. Rather, it means that I have the disposition to explain what I do and who I am in terms of a narrative. At the same time, this narrative self-understanding shapes my dispositions. A self-narrative is a largely implicit story through which I experience and organize my life. For instance, a feeling of financial security or a high sense of self-worth, typically rooted in one's past and integrated into the self-narrative, will influence how one acts and feels in everyday life, even if one does not consciously think about it. ${ }^{10}$

\section{Defending narrativism}

An evaluation of DBS in terms of narrative identity has been criticized on two grounds: that we can disvalue parts of our narrative and that it neglects the self here and now. ${ }^{11}$ I will reject both points of critique. It has been argued that we may sometimes be overall better off breaking the narrative if we disvalue parts of it. For instance, a patient with long term severe OCD would stick closer to her selfnarrative if she would continue being obsessed and compulsive. Not the fact that it is a central part of the self-narrative tells us whether it is part of her authentic self but her value judgment of the illness. Some could value their obsessive behavior, for instance a successful academic for whom this obsession over detail proved helpful in her career, whereas compulsive hand-washers may wish they could stop. However, narrative self theorists would not deny that we can disvalue parts of our history. A self-narrative is more than just a chronology of life-events. It reflects personal evaluations through editing, commenting or both. ${ }^{12} \mathrm{~A}$ self-narrative is edited insofar as it is an abridgment of one's actual life. We do not remember every detail of our lives and not everything we can possibly remember plays a significant role in the self-narrative. Self-narratives have certain focal points. Although self-deception and wishful thinking can play a role in this kind of editing through abridgment and focus, it does not necessarily lead to a less truthful narrative. This highlighting of some events and ignoring of others is one way in which what we deem valuable can be represented in the narrative. Another way is through commentary or a personal perspective. Self-narratives are not neutral lists of all the experiences of one's life. The stories of 
our lives are colored by our views on what occurred. A disease like OCD will not take a neutral position in the narrative of a person suffering from it. Her narrative includes the struggles that come with the symptoms and the attitude she takes towards her obsessions, as well as her wish to get rid of the disease. By including our personal perspective, on how we feel and think about life-events and how we interpret them, at the time they occur as well as retrospectively, our evaluative outlooks become part of the selfnarrative.

The person suffering from OCD would not stick closer to the narrative if she would refuse therapy and continue having OCD. Given her wish to get rid of the disease, it would instead be a disrupted narrative if she would not take the chance to get healed. The person that hates her disease does not seem continuous with the person that refuses to get healed (assuming there are no other reasons speaking against treatment). Narrative continuity and coherence are not equal to constancy. Many figures in great literary narratives undergo drastic life-changes without thereby making the story incoherent. If the story remains psychologically intelligible it can be continuous and coherent without exhibiting constancy (see section "Sustainability").

The further claim, that by focusing on narrative coherence the impact on the self here and now is neglected, does not hold either. Present values, outlooks, and interests are very much part of the selfnarrative. To ignore them for the sake of constancy would break narrative coherence. Moreover, in order to understand the self here and now a diachronic perspective is in many ways helpful, if not necessary. Most self-defining aspects are of a diachronic nature. They have a certain developmental history that shapes the way they are right now. We cannot value something for five minutes, have a certain trait or disposition just right now and also emotional connections develop over time. Not every last aspect of an individual's identity is historically grown - there surely are innate features and some are decided on the spot - but much of who we are is the result of where we came from. To just look at a person at a certain time-slice gives an incomplete picture which may not be a good basis for evaluating that person's needs, values and characteristics. The narrative perspective does not neglect the present self - to the contrary, it can provide a deeper understanding of it.

\section{Narrative authenticity}

I suggest that authenticity should be construed in narrative terms. It has been pointed out that there is a difference between narrative identity and authenticity. ${ }^{13}$ I agree, those are two different concepts which should not be confused. The narrative self view is, first of all, a theory of the self. Based on this selfconception we can define conditions for the persistence of this narrative self or conditions for its authenticity. The narrative self view is the basis for narrative authenticity but authenticity imposes two further requirements on the self-narrative: sustainability and self-definition. 


\section{Sustainability}

An authentic person has a sustainable self-narrative and acts in accordance with this self-narrative. In broad terms, a sustainable self-narrative does not require too much work to uphold because it is not in tension with one's lived experiences. It accurately and coherently represents them. In an unsustainable narrative, aspects of the story are off because relevant actions, emotions, thoughts or other personal facts are ignored or suppressed. A sustainable self-narrative is not in conflict with relevant 1) facts about one's subjective experience, such as one's emotions, thoughts or intentions. For instance, someone that sees herself as a loving sister but is actually always repelled or angry when she sees her siblings needs to ignore or suppress those feelings in order to uphold the loving-sister narrative. Emotions or thoughts do not have to be endorsed in every case but their existence should not be ignored and ideally tried to be explained. 2) The self-narrative accurately represents relevant objective facts about oneself, for instance one's nationality, body features or facts about actions and life events. If someone is a helpful person according to his self-narrative, but in fact, he constantly refused to help people, he has to suppress or ignore the memory of those actions. On top of that, he has to ignore or deny the accounts others give of his actions. Those two kinds of facts put constraints on how a self-narrative can be construed authentically. A sustainable self-narrative acknowledges not only who you were in the past, but also the boundaries of present actions, emotions, thoughts, and other facts. Some actions may just not be a real option for me while I might feel an overwhelming pull to do others.

A sustainable narrative requires extended self-knowledge. However, the facts one needs to acknowledge in order to have a sustainable narrative are only those which are accessible to oneself. For instance, Truman Burbank of the movie The Truman Show can live an authentic life, even if he does not know that he is the star of a TV show. However, it would be inauthentic if he found the cameras but ignored the truth they imply. The kind of contradiction that makes a narrative unsustainable arises only when the person has access to the relevant information. However, normally, reality just confronts us with facts - you are simply not fast enough to participate in the Olympics, you get scared and stressed in high up places, she told you she does not like you. Reality does keep a check on the self-narratives but only insofar as those facts actually reach us. We are not supposed to acknowledge truths about us we never had a chance to know.

Besides agreeing with one's experiences, a sustainable self-narrative is also coherent. A narrative is easier to uphold if it makes sense and the elements of the story build on and support each other. A selfnarrative is coherent if it succeeds at making single episodes of a person's life and her characteristics intelligible by integrating them in a wider context. It tells a psychologically intelligible story of a person. In a bad book, the character may exhibit traits, beliefs, and actions that do not fit together. The reader wonders how a person with such traits could do this action or hold that view. In a coherent self-narrative, a single element of the story makes sense in the light of the rest of it. Coherence is what holds the story together, connects single episodes and unites them in an overarching narrative. For instance, the episode of a person that goes to a store to buy a book is part of the story of this person being invited to a birthday 
party for which he needs a gift. This episode is itself part of a narrative about the relationship of those two people as well as of general stories about gifting culture on birthdays. ${ }^{14}$

The coherence of the narrative authenticity view is based on psychological intelligibility and does not require an overarching theme, quest or meaning. 15 The episode of someone buying a birthday present is perfectly intelligible even if it is not part of an overall life-quest. Neither does narrative coherence imply that there is no room for change and ambiguity. In literature and cinema, character changes and ambiguity are typically a central element of the story. This in no way diminishes the coherence of the story. Even dramatic and far-reaching changes, as well as ambiguity and conflicting views, can be intelligible in a narrative because they do not just come into existence out of nowhere. A fundamental change of character can be made sense of if it is explained, for instance through a transformative experience. ${ }^{16}$ There are reasons why someone ended up having an ambiguous relationship with his father or why someone wants to be both, a traveling artist as well as a settled accountant. Through a narrative even conflicting, ambiguous and changing views can fit together and be mutually supporting. They are accounted for in the narrative. Narrative coherence can do justice to the complex and messy human psychology in a way that coherence as mutual compatibility of Pugh et al.'s account does not.

Of course, your narrative does not have to be perfectly coherent and accurate to the last detail in order to be sustainable. With the self-narrative we connect single episodes of our lives and attribute meaning. This does not require perfect accuracy or coherence. The relevant aspects are the ones that shape your narrative. Minor parts that are generally in agreement with the bigger picture can be misremembered without a problem and a narrative is sustainable even if it is not fully coherent, e.g. if it fails to make minor aspects intelligible in the light of the overall person. In fact, a perfect, tidy narrative would be suspicious. A misrepresentation of an aspect of yourself is problematic if you would have to adapt large parts of the self-narrative in order to acknowledge it. ${ }^{17}$ Furthermore, a sustainable self-narrative can change. It can be necessary to adapt it to new developments and insights. I can change my view on past experiences and interpret them differently. Through this flexibility, a narrative can gain stability. The coherence of a narrative is dynamic and provisional. Only if we can integrate new views and insights we can sustainably hold on to our self-narrative.

\section{Self-definition}

The demand for sustainability ensures that the authentic narrative is accurate and that it depicts a psychologically intelligible person. Now, a second requirement is introduced which prevents that the person in the self-narrative is in some sense empty or under defined. Whether authenticity is understood as selfdiscovery or as self-creation, an authentic person is well-defined. ${ }^{18}$ To be authentic entails that the question of who you are does not have many disparate and equally right answers. If a self-narrative is too vague, or if it seems as though a different one would fit equally well or better, the self is not sufficiently well-defined in order to be authentic. 
A source of a less well-defined self is self-definition which overly relies on terms of potentiality. An example of this is Frank Wheeler in Richard Yate's Revolutionary Road. ${ }^{19}$ Frank always thought of himself as having an exceptional vocation, as someone with a significant career ahead to which he would be fully dedicated. Until he would know what his calling was, he started working an unfulfilling office job in order to provide for his family. He took an ironic, distanced stance towards his job, his ordinary suburban home, as well as most of his neighbors and colleagues - he saw himself as above all that. His wife shared his view and suggested they move to Paris where she would work while he could find himself and figure out what he actually wanted to do. However, this suggestion instantly frightened Frank. What if there was nothing much to be found? A combination of his fear of self-discovery and personal circumstances led him to eventually abandon this plan and to finally identify with his office job. Yet, in the end, it is not entirely clear whether he actually found some kind of fulfillment in his job or whether he just resigned and stopped hoping for more. Frank's example shows that if someone constructs an identity overly reliant on potentiality, he ends up being empty and undefined. Frank is unsure whether he actually is the person he thought himself to be because he never seriously acted on those alleged dispositions. A life in potentiality never creates a fact of the matter about who one is. For a well-defined self, such potentialities eventually have to be actualized. Actions can confirm and define self-narratives, not only towards third parties by making mental states visible, but also towards the person the narrative is about. They cannot be doubted the same way as intentions, thoughts, and emotions, which could be self-deceived. If someone actually acts selflessly it is difficult to contradict that she is a selfless person. To be authentic we have to eventually act on our alleged features. ${ }^{20}$

Another way in which a person can end up poorly defined becomes clear if we distinguish between what a person does and what she suffers according to his narrative. ${ }^{21}$ Both can be integral to the self-narrative. An accident that has paralyzed someone will be a central part of her narrative and substantially change how the narrative will continue, even if it is purely contingent and just happened to her. There are many instances where it is not obvious whether something was self-authored or not. In some cases, it is possible to externalize one's own doings and describe them as sufferings. For instance, someone could say it was not really himself that insulted his friend, it was because of his brain tumor or because the circumstances somehow forced him. Those externalized parts of the narrative are not seen as representative of who he is and are not fully self-owned. ${ }^{22}$ Even central parts of the self-narrative can be externalized and not self-owned. However, this comes at a cost: it leaves the self poorly defined. If everything just happens to you and you do not shape your life through decisive actions it is not clear what kind of person you are. It remains a matter of speculation how you would have acted, given the chance. This is also a problem in Frank's case. Most of the major factors of his life, his job, his house, his children, somehow just happened to him. Or at least this is the perspective he takes. But the reader, and ultimately also Frank, is led to question this story. Maybe this is just a lie he tells himself because he cannot bear his mediocracy. His identity remains in abeyance because he does not fully recognize those actions as his own. A self-narrative that is not self-directed in that sense leads to a poorly defined self. 
An under defined self can be identified if the self-narrative leaves room for disparate, more comprehensive and coherent counternarratives. Of course, the factual situation always allows for a variety of slightly diverging stories about a person. An action could be interpreted differently, other aspects of a person could be in focus or the narrative could have a shifted perspective. A poorly defined self, however, leaves the option for counternarratives which are profoundly different while remaining believable and psychologically intelligible, and which may be able to explain aspects the original self-narrative cannot account for. Such a counternarrative could be told from a third- or first-person point of view. The crucial point is not who or whether someone actually construes such a counternarrative but that in a case of inauthenticity a more coherent, intelligible and extensive counternarrative remains possible. For instance, if we ascribe ourselves traits only based on potentiality it is possible to construe a counternarrative which excludes them. In Frank's case, we could tell a story about him in which he never was outstanding but self-deluded and unable to bear how average he is, or one in which he lost his former exceptionality over the years because he adapted to his conventional life. In the end, there is no clear answer which of those stories is the right one. We run into similar problems if we describe everything as just happening to ourselves. It remains unclear how we would have acted if the situation would have allowed us to. A self-narrative that is not actualized and self-directed does not exclude problematic counternarratives.

The narrative authenticity approach is a dual-basis view, balancing the possibilities and constraints of self-discovery and self-creation. Those tensions within the concept of authenticity are fertile and reflect the complexity of human psychology. ${ }^{23}$ Narrative authenticity is about self-discovery because for a sustainable narrative we generally have to know and acknowledge the brute facts about us, ranging from nationality and body appearance to facts about life events and actions, as well as our emotions, intentions and thoughts. Moreover, it is possible to "add another chapter" to your narrative if you learn something new about yourself. Including new characteristics into the narrative can also mean to rearrange and revise previous aspects. But narrative authenticity is more than just discovering and acknowledging facts about oneself. With the narrative we mark some events as more important than others, we ascribe ourselves character traits, we connect actions and events to overarching goals, we reject some actions and embrace others. Those aspects of the narrative are to some degree the result of creative decisions. Based on the same brute life-facts we can construct different stories about a person. Which one we end up with is a question of choice. There can be equally true but different perspectives on a person's life. But selfcreation not only comes into play by how we interpret and relate to past and present actions. We can also shape our future and work on ourselves in order to deliberately change who we are. Of course, there are a lot of things you cannot choose or control in your self-narrative. But to ignore the degree of responsibility you have over your life by letting it be directed by coincidences or other people's views can leave you either with an unsustainable narrative or an undefined self. Either you do things you do not want to, which means you have to suppress or ignore the contradicting thoughts and emotions, or you are not the author of your actions and end up in the same position as Frank Wheeler. 
In conclusion, according to the narrative authenticity view, to be an authentic person one needs to have a self-narrative which is not in tension with one's lived experience and which does not leave room for vastly different and more coherent counternarratives. ${ }^{24}$ The sustainability requirement flags parts of the self-narrative which misrepresent oneself. It ensures that I am factually right about who I $\mathrm{am}$. The lack of counternarratives ensures that the self is well-defined, such that the answer to the question of who I am is not just one among many different but equally right ones.

\section{Advantages of narrative authenticity}

Now the question remains why we should prefer the narrative authenticity view over other approaches, in particular the two proposed in the discussion this paper responds to, Pugh et al.'s account of cohering values and beliefs and Nyholm and O'Neill's tolerable values view. The arguments I bring forward pertain to 1) the criteria of guidance and fit for patient's experience and use, 2) advantages regarding the underlying concept of the self 3) the importance one's past bears on authenticity and 4) the distinction between authenticity and autonomy.

First of all, narrative authenticity can satisfy the two requirements Pugh et al. and Nyholm and O'Neill lay down: providing guidance and capturing the experiences people with DBS and with AN have regarding authenticity. It has been argued that the kind of guidance for self-fulfillment patients seek when turning to the idea of authenticity requires elements of self-discovery. Pure self-creation based views ignore that the question of authenticity precedes and informs choices on self-creation. ${ }^{25}$ Narrative authenticity can provide this kind of choice-independent guidance. In particular the criterion of sustainability calls for self-discovery and can provide guidelines for decision-making and self-fulfillment.

Furthermore, the narrative authenticity view can accommodate the different experiences of individuals with DBS or with mental disorders. Some see the disease as an integral part of their authentic self, whereas others reject it and see themselves as alienated through the illness. The same dichotomy can be found between the self under the influence of DBS or medication and the untreated person. ${ }^{26}$ Those different views can be explained through the distinct ways the diseased or the treated states are framed in the narrative. Someone might see her mental illness as a contingent part of herself. She construes herself in her narrative as a healthy person to which this disease happened. The medical treatment can either be seen as helping to find a way back to this state or as a further external source of alienation. Others may frame the disease as a part of themselves, not as coming from the outside but as a selfconstituting aspect of their identity. Some people see both states as an integral part of an authentic narrative and are able to construe a self-narrative which integrates both. Narrative authenticity is compatible with all those views, including the last one, which, as Pugh et al. admit, poses a problem for their account.

According to the narrative authenticity view, DBS can both increase and lower the patient's authenticity. DBS can induce abrupt changes in body condition, personality, and personal 
circumstances. Those changes can be hard to integrate into an ongoing, coherent narrative. On the other hand, DBS can have a positive effect on authenticity by improving the health of the patients. DBS can help them to attribute aspects of their life to themselves which used to be externalized. Aspects of their lives, formally regulated by the disease and externalized, can become self-governed through DBS. Moreover, a narrative approach can show ways how to cope with DBS induced changes by revising the self-narrative. Such a method of co-authoring a new self-narrative already finds application in narrative psychology. Although more work would be needed to review the effects of DBS and mental disorders on narrative authenticity, it is possible to assess that this approach is compatible with the varying experience individuals with DBS or with mental disorders make regarding their authenticity.

Second, I want to address the self-conceptions underlying the different approaches to authenticity. With a certain view of authenticity comes a certain concept of the self. The self is e.g. viewed as something to be created or discovered or as having a core and a periphery. Thus, a convincing approach to authenticity should be based on a convincing self-conception. Narrativism provides a concept of the self which has proven fruitful not only in various philosophical discussions, in particular on personal identity, ${ }^{27}$ but also in psychology. ${ }^{28}$ This view on authenticity can be incorporated into an existing framework of related topics. Moreover, in contrast to other views, narrative authenticity can avoid making an overly strong distinction between one's true self and the actual one. If the true self is defined as an innate essence, or as what one values it is completely independent of how one actually acts. An example from David DeGrazia ${ }^{29}$ illustrates this: Nina and Xena are both smokers. Nina sees smoking as out of character for her and wishes she never started. Xena identifies with her addiction as a way of expressing her contrarian views. According to DeGrazia, being a smoker is only part of Xena's identity but not of Nina's because the latter does not identify with it. Such views neglect the extent to which individuals are defined by their behavior, thoughts, and emotions. The question of how you relate to what you do, feel or think, whether you embrace or reject it or see it as out of character, clearly matters. However, just because you do not fully identify with an action, because it is incoherent with other views you hold or because it is less tolerable, does not mean it is not part of who you are. To be authentic, such actions or characteristics should be acknowledged as part of your identity. You may still want to work on them but they are nevertheless you. The narrative authenticity view acknowledges the importance of how I relate to an action, thought or feeling, without allowing me to disregard it as not part of myself. Thereby, the unnatural distance between the true self and the actual self is abolished.

Third, narrative authenticity can do justice to the importance one's past bears on authenticity. According to Pugh et al.'s view for instance, as soon as a value is given up and no longer part of one's canon of mutually compatible values and beliefs, it is in no sense part of one's identity anymore. They seem to be committed to that view even though they want to advance a diachronic account. However, it seems that authenticity as self-discovery requires understanding and acknowledging one's past. If we did not know that the great Gatsby used to be poor and that he reinvented himself we would not fully understand his person and neither would he if he ignored those facts about himself. The fact that Gatsby 
was poor is part of who he is. Authenticity as narrative sustainability requires him to acknowledge his past. Even if past views contradict one's current canon of values, they continue to be a factor of one's identity, as shown in a quote from a person commenting on her AN: "I've gone through it, so I feel like it kind of belongs to me now, and that even though I don't want it, it's still part of me in a way." 30

One might worry that narrative authenticity puts an excessive focus on one's past, that to be authentic we should not dwell in the past but live in the moment. However, narrative authenticity does not demand that we always consciously think about our narrative. The self-narrative is largely implicit. Moreover, the question of whether someone is authentic right now only makes sense in the light of the person as a whole, which is essentially diachronic. To know who you are right now requires at least an implicit understanding of where you come from. This does not mean you are stuck in the past.

Fourth, a different problem area of views based on rational endorsement and coherence is that they define authenticity as so similar to autonomy that they lose some of its distinctive features. Many definitions of autonomy are based on a hierarchy of values, where one value is prioritized over another. ${ }^{31}$ An action is autonomous if it is in accordance with this hierarchy because it is a result of a rational endorsement. Pugh et al.'s approach is centered around a rationally endorsed hierarchy of mutually compatible values and beliefs. It is broadly based on Laura Waddell Ekstrom's coherence account of personal autonomy. ${ }^{32}$ However, it seems that conflicts of values and beliefs need not be settled for questions of authenticity. One can be authentically conflicted and ambiguous. For some people, it may be a fundamental aspect of who they are to highly value both family and career and to regularly face situations in which those values are not compatible. It seems counterintuitive that one should be able to provide a ranking of values in order to be authentic. Most would probably be hard-pressed to decide between their values independent of a concrete situation. Actions can force us to choose to do either $\mathrm{x}$ or y, thus it may make sense to set coherence as mutual compatibility as a standard to judge the autonomy of actions. But identities do not necessitate such decisions and it seems unhelpful, if not impossible, to do so. A person should not be considered less authentic if he can only make out roughly distinguishable groups of generally more or less important values. Authenticity warrants a different kind of coherence than autonomy. Coherence as mutual compatibility, which obliges me to settle any conflict between my desires and beliefs, seems like an almost impossible and not particularly desirable ideal which runs the risk of simplifying human psychology. Narrative coherence, on the other hand, can make sense of conflicts and ambiguity of values. Through a person's life-story conflicts and ambiguities become intelligible and unified. The narrative self can be coherent without resolving whether the person values x over $\mathrm{y}$, which seems like a more desirable basis for authenticity.

There is another distinction between autonomy and authenticity that has been neglected due to a focus on agency. According to the ideal of authenticity, it can sometimes be more important to follow one's emotions instead of autonomously chosen principles, in order to avoid alienation or an identity crisis. ${ }^{33}$ Discipline and control over one's impulses may be necessary to be autonomous but it can affect authenticity negatively. The sole focus on mutually compatible values and rational beliefs has 
problematic consequences for Pugh et al.'s account. According to it, even self-mutilating decisions are authentic because the importance non-rational parts can have for one's identity is neglected. For instance, a woman who suppresses her strong attraction for another woman because of her Christian values would be considered authentic in Pugh et al.'s view. Because persons are only seen as rational decision-makers, this account cannot do justice to other aspects of the individual. It does not acknowledge that it can be unauthentic to suppress parts of oneself, even if it is done through an endorsed, rational decision. Emotions, skills, habits and contingent elements of our life can fundamentally shape and define us, even if they are not rationally endorsed. A self-narrative includes all those elements. Thus, it can give a much fuller account of an individual's identity without losing sight of the importance of rationally endorsed values and beliefs.

\section{Notes}

1. Although more studies are needed to clarify to what extent those changes are directly caused by the DBS implant and how often such changes occur, see Gilbert F, Vinaña JNM, Ineichen C. Deflating the "DBS causes personality changes" bubble. Neuroethics 2018:1-17, it is nevertheless ethically relevant to discuss those changes and the involved concepts, see Pugh, J, Pycroft, L, Maslen, H, Aziz, T, Savulescu, J. Evidence-Based Neuroethics, Deep Brain Stimulation and Personality - Deflating, but not Bursting, the Bubble. Neuroethics 2018:1-12.

2. Erler A, Hope T. Mental Disorder and the Concept of Authenticity. Philosophy, Psychiatry, \& Psychology 2014;21(3):219-32.

3. Pugh J, Maslen H, Savulescu J. Deep Brain Stimulation, Authenticity and Value. Cambridge Quarterly of Healthcare Ethics 2017;26(4):640-57.

4. Nyholm S, O’Neill E. Deep Brain Stimulation, Continuity over Time, and the True Self. Cambridge Quarterly of Healthcare Ethics 2016;25(4):647-58; Nyholm S, O’Neill E. Deep Brain Stimulation, Authenticity and Value: Further Reflections. Cambridge Quarterly of Healthcare Ethics 2017;26(4):658-70.

5. See e.g. The President's Council on Bioethics. Beyond Therapy. Biotechnology and the Pursuit of Happiness. New York: Regan Books; 2003; Elliott C. Better than well: American medicine meets the American dream. New York: Norton; 2003; Rousseau J-J. The Confessions and Correspondence, Including the Letters to Malesherbes. Hanover, N.H. etc.: University Press of New England; 1995.

6. See e.g. Sartre J-P. Being and Nothingness. London: Routledge; 1991; DeGrazia D. Prozac, Enhancement, and Self-Creation. The Hastings Center Report. 2000;30(2):34-40.

7. See note 3, Pugh, Maslen, Savulescu 2017, at 645.

8. See note 4, Nyholm, O’Neill 2017, at 664 .

9. See note 4, Nyholm, O’Neill 2016, at 651.

10. Schechtman M. The constitution of selves. Ithaca NY, London: Cornell University Press; 1996, at 110-1.

11. See note 4, Nyholm, O’Neill 2016, at 650-1 and note 3, Pugh, Maslen, Savulescu 2017, at 644-6, 650.

12. Glover J. I: the philosophy and psychology of personal identity. London etc.: Penguin Books; 1988.

13. See note 3, Pugh, Maslen, Savulescu 2017, at 644.

14. MacIntyre AC. After virtue. Notre Dame: University of Notre Dame Press; 1984.

15. In contrast to narrative self views of e.g. Charles Taylor or Alasdair MacIntyre. See note 14, MacIntyre 1984; Taylor C. Sources of the Self. Cambridge: Harvard University Press; 1989.

16. We may not be able to make a rational, first-personal decision about a transformative experience before undergoing it, but looking back we can make sense of the changes the experience initiated. See Paul LA. Transformative experience. Oxford: Oxford University Press; 2014.

17. See note 10, Schechtman 1996, at 122-5.

18. This does not imply that one cannot be authentically conflicted or ambiguous, more on that in the section "Advantages of narrative authenticity".

19. Yates R. Revolutionary road. London: Vintage Books; 2007.

20. In particular the existentialists stressed the importance of action for self-definition and authenticity. 
21. In psychology, this is typically discussed under the term self-efficacy.

22. Heidegger discussed authenticity in terms of a self-owned life. To be authentic, or eigentlich, a person has to take action in a self-determined and independent manner. By externalizing central parts of the self-narrative and describing them as happening to oneself, this ownership necessary for authenticity is lacking.

23. Parens E. Authenticity and Ambivalence: Toward Understanding the Enhancement Debate. The Hastings Center Report. 2005;35(3):34-41.

24. I mainly discussed the authenticity of persons, defined as having a certain kind of self-narrative. A single action, thought or feeling is authentic if it is in accordance with such a self-narrative. Someone has had an authentic life if he mostly acted, thought and felt authentically.

25. See note 2 Erler, Hope 2014, at 219-32.

26. See note 2 Erler, Hope 2014.

27. For an overview see Schechtman M. The narrative self. In: Gallagher S, ed. The Oxford handbook of the self. Oxford: Oxford University Press; 2011:394 - 418.

28. For an overview see Crossley ML. Introducing narrative psychology: self, trauma, and the construction of meaning. Buckingham: Open University Press; 2000.

29. See note 6, DeGrazia 2000.

30. Hope T, Tan J, Stewart A, Fitzpatrick R. Anorexia Nervosa and the Language of Authenticity. Hastings Center Report 2011;41(6):25.

31. Korsgaard, CM. Self-Constitution. Oxford: Oxford University Press; 2009. Frankfurt, HG. Freedom of the Will and the Concept of a Person. The Journal of Philosophy 1971;68(1):5-20; Ekstrom LW. A Coherence Theory of Autonomy. Philosophy and Phenomenological Research 1993;53(3):599-616. I do not advance a view on autonomy at this point. I discuss the rational endorsement approach because it is the basis of Pugh et al.'s notion of authenticity.

32. See note 3, Pugh, Maslen, Savulescu 2017, at 646 and note 30, Ekstrom 1993.

33. Alessandro Ferrara discussed this distinction between autonomy and authenticity in his analysis of Rousseau's work. See Ferrara A. Modernity and authenticity: a study in the social and ethical thought of Fean-facques Rousseau. Albany, NY: State University of New York Press; 1993. 